\title{
Comparison of caproic acid and monolaurin with zinc oxide and benzoic acid; effect on growth performance of weaned pigs
}

\author{
N. Portocarero \\ Feed, Food and Future, Brookside, Brecon Road, Hay-on-Wye, HR3 5DY, United Kingdom; np@feedfoodfuture.com
}

Received: 8 September 2021 / Accepted: 19 January 2022

(c) 2022 N. Portocarero

RESEARCH ARTICLE

\begin{abstract}
Medium chain organic acids (MCOA) offer the potential to replace zinc oxide, without dependence on antibiotic use, and can replace or reduce the use of benzoic acid in pig production. A study was conducted to evaluate the effects of caproic acid (C6) and $\mathrm{C} 12$ monolaurin $(\mathrm{C} 12 \mathrm{M})$ on the growth performance of weaned pigs, in comparison with zinc oxide $(\mathrm{ZnO})$ and benzoic acid (BA). Specifically, the trial examined whether MCOA, at a reduced inclusion level of BA, could maintain performance levels of pigs similar to those receiving a higher inclusion level of BA. In total, 240 pigs from weaning until $27 \mathrm{~d}$ post-weaning were used in a completely randomised block trial with six treatments and eight replicate pens per treatment. Treatments were: (1) control (CON), basal diet (BD); (2) $\mathrm{BD}+\mathrm{ZnO}$ (ZnO); (3) BD+5,000 mg/kg BA (BA); (4) BD+2,500 mg $/ \mathrm{kg} \mathrm{BA}+2,000 \mathrm{mg} / \mathrm{kg} \mathrm{C} 12 \mathrm{M}+700 \mathrm{mg} / \mathrm{kg} \mathrm{C6}\left(\mathrm{BA}_{\text {low }} / \mathrm{MCOA}\right)$; (5) $\mathrm{BD}+2,000 \mathrm{mg} / \mathrm{kg} \mathrm{C} 12 \mathrm{M}+700 \mathrm{mg} / \mathrm{kg}$ C6 (MCOA); (6) BD+1000 mg/kg C12M+700 mg/kg C6 (MCOA ${ }_{\text {low }}$ ). Feed and water were provided ad libitum. Pigs receiving BA or BA low $/ \mathrm{MCOA}$ had improved feed conversion ration (FCR) during the period $0-14$ days, compared with control pigs (1.02 vs $1.17, P<0.05 ; 1.06$ vs $1.17 ; P=0.084$, respectively). The FCR of pigs receiving $\mathrm{BA}_{\text {low }} / \mathrm{MCOA}$ was similar to those receiving $\mathrm{BA}$ at the higher inclusion-level. Pigs showed good health throughout the study, as indicated by clinical and faecal scores. Replacement of $\mathrm{ZnO}$ was inconclusive and further studies with more challenging health conditions are required to conclude benefits.
\end{abstract}

Keywords: antibiotics, pigs, performance, replacement, organic acids

\section{Introduction}

It is well established that the use of antibiotics in in pig production need to be reduced in order to slow the development of antimicrobial resistance which occurs through genetic mutation (vertical transmission) or acquiring resistance genes from another bacterium (horizontal transmission), including other species of bacteria (Munita and Arias, 2016). Antimicrobial resistance spreads throughout the environment as the bacteria move through, for example, sewage, waste and livestock products (Woolhouse et al., 2015) and is present at unacceptably high levels in pig production systems (Holmer et al., 2019; Pollock et al., 2020; Zhang et al., 2019). In the United Kingdom, the pig sector is still heavily dependent on prophylactic use both of antibiotics and zinc oxide $(\mathrm{ZnO})$.
Despite voluntary reductions in recent years, antibiotics continue to be routinely administered to pigs as medicated feeds for a two-week period after weaning to prevent lowlevel infections.

Antibiotic use in 2019 was similar to levels reported in 2018, at $110 \mathrm{mg} /$ population correction unit (PCU), having fallen $60 \%$ in the three years prior (AHDB, 2019). This figure indicates that $110 \mathrm{mg}$ of antibiotic active ingredient was used for every $\mathrm{kg}$ of bodyweight at time of treatment. In the first half of 2020, antibiotic usage dropped to $104 \mathrm{mg} / \mathrm{PCU}$; a significant achievement towards the $99 \mathrm{mg} / \mathrm{PCU}$ target set in 2017 (AHDB, 2020). However, new targets have now been established for a 30\% reduction between 2020 and 2024 (RUMA, 2020). Regulation EU 2019/4, which comes into force in January 2022, will prohibit the prophylactic 
use of antibiotics in the European Union, except for very exceptional cases and to treat individual animals.

In parallel, there is an urgency to remove $\mathrm{ZnO}$ from piglet starter feeds to meet legislation in place as a result of environmental and toxicity concerns, including microbial cross-resistance. The European Medicines Agency's Committee for Medicinal Products for Veterinary Use concluded that the overall benefit-risk balance for veterinary medicinal products containing $\mathrm{ZnO}$ was negative, as benefits for the prevention of diarrhoea in pigs did not outweigh the risks for the environment. They recommended withdrawal by 2022 of the existing marketing authorisations for veterinary medicinal products containing $\mathrm{ZnO}$ (European Commission, 2017). $\mathrm{ZnO}$ was estimated to be used in 70-90\% of weaned pig rations in 2017 (NPA, 2017), although it is expected that this figure has since reduced in response to pending legislation. There are concerns that the removal of $\mathrm{ZnO}$ may lead to a rise in antibiotic dependence. Furthermore, the cost of endemic pig disease, estimated at around $£ 190-250$ million/annum in the UK (ProHealth FP7 consortium, 2015), could increase if antibiotics are withdrawn without viable alternatives. Benzoic acid is widely used to reduce and replace in-feed antibiotics and $\mathrm{ZnO}$, but there may be concerns about long-term use of high levels in pig feeds.

There is an ongoing drive to develop alternatives to antibiotics and $\mathrm{ZnO}$. Among the candidates of interest, medium chain organic acids (MCOA) have received attention interest due to their strong antimicrobial properties. These are monocarboxylic acids which are unbranched and unsaturated, and consist of caproic acid (C6:0, hexanoic acid), caprylic acid (C8:0, octanoic acid), capric acid (C10:0, decanoic acid) and lauric acid (C12:0, dodecanoic acid). Monoesters of free fatty acids may be formed; for example, monolaurin is a monoester formed from glycerol and lauric acid. The antimicrobial activity of MCOA has been extensively reviewed by Hanczakowska (2017). The undissociated acid molecules penetrate the phospholipid bilayer membrane of bacteria and enter the cell where they dissociate in the alkaline $\mathrm{pH}$. The $\mathrm{pH}$ of the cell cytoplasm is lowered, suppressing cytoplasmic enzymes and nutrient transport systems, which leads to cell death. Several studies have shown stronger inhibitory effects with MCOA than with short or long chain organic acids (Hanczakowska et al., 2013; Hassinen et al., 1951; Nieman, 1954). There are conflicting reports about the relative antimicrobial efficacy of different MCOA. Only caprylic acid (C8:0), and, to a lesser extent, capric acid (C10:0) have shown significant antimicrobial activity against two strains of Escherichia coli in one study (Marounek et al., 2003). However, in another study, both lauric acid (C12:0) and caprylic acid (C8:0) had the ability to damage the cytoplasmic structure of bacteria (Skrivanová et al., 2006). Lauric acid was shown to disrupt Clostridium spp. cell membranes and cytoplasm (Shilling et al., 2013). Monolaurin was shown to be more active than the free fatty acids against gram positive bacteria (Batovska et al., 2009). Other in vitro studies (Neath et al., in press), confirmed the efficacy of monolaurin against Gram positive bacteria, Staphylococcus aureus and Streptococcus suis, whereas caproic acid had activity against gram negative bacteria, including Salmonella typhimurium and E. coli, as well as against gram positive bacteria. A combination of monolaurin $(\mathrm{C} 12 \mathrm{M})$ and caproic acid (C6:0) may therefore be beneficial to replace prophylactic $\mathrm{ZnO}$, without resorting to antibiotic use, and partially replace benzoic acid (BA) without any reduction in pig performance.

To test this hypothesis, the following study was conducted to evaluate a blend of MCOA consisting of C12M and C6:0 on the growth performance of weaner/grower pig in comparison with standard $\mathrm{ZnO}$ or BA.

\section{Materials and methods}

\section{Animals and trial design}

The trial was carried out in accordance with the U.K. Animals (Scientific Procedures) Act, 1986 and associated guidelines. Two hundred and forty (Large White $\times$ Landrace) $\times$ Danish Duroc pigs selected for use in the trial were weaned at an initial weight $8.1 \pm 1.41 \mathrm{~kg}$ (mean \pm SD) at $26.0 \pm 1.25$ days of age. The experiment consisted of 48 pens, each containing five mixed sex pigs. Start weight, sex and litter of origin were balanced across treatments within replicates. Pens within each replicate were randomly assigned to one of the six dietary treatments shown in Table 1 . Pens measured $2.8 \times 2.0 \mathrm{~m}$ with plastic coated fully slatted flooring (without bedding) and nipple drinkers. Pigs remained on the trial for 27 days after weaning, with an average final BW of $19.82 \pm 3.43 \mathrm{~kg}$. Feed and water were provided ad libitum throughout the experimental period.

\section{Dietary treatments}

A two-phase feeding programme was used: phase 1 from weaning to $\mathrm{d} 14$ and phase 2 from $\mathrm{d} 15$ to $\mathrm{d} 27$. Diets were provided by a UK commercial feed producer according to a commercial specification. Feed-grade $\mathrm{BA}, \mathrm{ZnO}$, caproic acid and monolaurin were obtained from commercial manufacturers. A standard level of BA inclusion $(5,000$ $\mathrm{mg} / \mathrm{kg}$ ), as used in previous studies, was reduced by $50 \%$ to determine whether a lower dose-rate could be mitigated by adding medium chain organic acids. The level of monolaurin was based on the commercially recommended level, reduced to $50 \%$ in the $\mathrm{MCOA}_{\text {low }}$ treatment. The level of caproic acid was reduced compared to the dose used in a previous trial, to determine whether a response could still be achieved, in combination with monolaurin. The level of $\mathrm{ZnO}$ used was the standard authorised dose- 
Table 1. Dietary treatments.

\begin{tabular}{|c|c|c|c|}
\hline Diet & Treatment $^{1}$ & $0-14 \mathrm{~d}$ of trial & $15-27 \mathrm{~d}$ of trial \\
\hline $\begin{array}{l}1 \\
2 \\
3 \\
4 \\
5 \\
6\end{array}$ & $\begin{array}{l}\text { Con } \\
\mathrm{ZnO} \\
\mathrm{BA} \\
\mathrm{BA}_{\text {low }} / \mathrm{MCOA} \\
\mathrm{MCOA} \\
\mathrm{MCOA}_{\text {low }}\end{array}$ & $\begin{array}{l}\text { Basal diet } \\
\text { ZnO (2,500 mg/kg zinc) } \\
\text { BA 5,000 mg/kg } \\
\text { BA 2,500 mg/kg; C12 M 2,000 mg/kg; C6:0 } 700 \mathrm{mg} / \mathrm{kg} \\
\text { C12 M 2,000 mg/kg; C6:0 } 700 \mathrm{mg} / \mathrm{kg} \\
\text { C12 M } 1000 \mathrm{mg} / \mathrm{kg} ; \text { C6:0 } 700 \mathrm{mg} / \mathrm{kg}\end{array}$ & $\begin{array}{l}\text { Basal diet } \\
\text { Basal diet } \\
\text { BA 5,000 mg/kg } \\
\text { BA 2,500 mg/kg; C12 M 2,000 mg/kg; C6:0 } 700 \mathrm{mg} / \mathrm{kg} \\
\text { C12 M 2,000 mg/kg; C6:0 } 700 \mathrm{mg} / \mathrm{kg} \\
\text { C12 M } 1000 \mathrm{mg} / \mathrm{kg} ; \text { C6:0 } 700 \mathrm{mg} / \mathrm{kg}\end{array}$ \\
\hline
\end{tabular}

${ }^{1} \mathrm{BA}=$ benzoic acid; Con = control; $\mathrm{MCOA}=$ Medium chain organic acids; $\mathrm{ZnO}=$ zinc oxide .

rate $(2,500 \mathrm{mg} / \mathrm{kg}$ in feed). The test additives were added by substitution of barley and pre-blended into $5.0 \mathrm{~kg}$ of wheat to facilitate uniform distribution, then pelleted through a commercial press using a $2 \mathrm{~mm}$ die. The nutrient specifications of the formulated diets are given in Table 2 . Diets were colour coded, to allow the trial to be run under blinded conditions.

\section{Measurements and analytical methods}

Individual pig weights were recorded on days $0,7,14,21$, and 27. Feed troughs were emptied daily from weaning to $\mathrm{d} 21$ and then at day 27 for the determination of pen feed intake. Average feed conversion ratio (FCR) per pen was calculated from body weight and feed intake measurements. Individual use of antibiotics, incidence of scours or other health problems and mortality were recorded. Faecal scores were evaluated by the same technician daily at the same time each day from Monday to Friday for the duration of the trial, using the following scoring system: 1 = firm, 2 $=$ soft, spreads slightly, $3=$ very soft, spreads readily, $4=$ watery, liquid consistency. Health scores were designated based on the proportion of pigs within a pen displaying signs of poor health with respect to mobility, demeanour or behavioural signs, and averaged over each feeding phase. For example, if a pen had 1 pig that seemed unwell it would score $0.2(1 / 5)$.

\section{Statistical analysis}

Data were analysed according to a randomised complete block design using the general linear model function of SPSS (version 21; IBM Corp., Armonk, NY, USA) with pen designated as the experimental unit. Data were checked for normality of residuals using the Kolmogorov-Smirnov test and homogeneity of variance, using the Levene's test prior to analysis. Week 1 and diet 1 FCR data variance was heteroscedastic, and were subjected to a Kruskal-Wallis

Table 2. Basal diet specifications.

\begin{tabular}{|c|c|c|c|c|c|}
\hline Ingredients (\%) & $0-14 d$ & $15-27 d$ & Nutrients ( $\%$ DM) formulated ${ }^{1}$ & $0-14 d$ & $15-27 d$ \\
\hline Barley & 15.00 & 17.31 & Crude protein & 21.64 & 21.14 \\
\hline Oats & 5.00 & - & Oil $A^{2}$ & 7.30 & 4.27 \\
\hline Wheat & 30.00 & 45.00 & Oil $B^{3}$ & 7.98 & 4.94 \\
\hline Soya, extruded $48 \%$ & 16.00 & 23.56 & NDF & 7.43 & 9.03 \\
\hline Soya, full fat & 3.00 & - & Ash & 5.29 & 5.17 \\
\hline Fish meal $68 \%$ & 5.00 & 4.00 & Calcium & 0.70 & 0.72 \\
\hline Dry skimmed milk & 3.00 & - & Phosphorus & 0.70 & 0.65 \\
\hline Whey & 14.44 & 4.65 & SID phosphorus & 0.44 & 0.38 \\
\hline Soya oil & 5.00 & 2.70 & Sodium & 0.18 & 0.19 \\
\hline Limestone & 0.20 & 0.57 & SID lysine & 1.37 & 1.23 \\
\hline Salt & 0.82 & 0.74 & SID methionine & 0.53 & 0.44 \\
\hline Lysine $\mathrm{HCl}$ & 0.35 & 0.31 & SID threonine & 0.89 & 0.80 \\
\hline Methionine & 0.20 & 0.15 & & & \\
\hline Threonine & 0.17 & 0.14 & Nutrients (\% DM analysed) & & \\
\hline Tryptophan & 0.03 & - & Crude protein & 21.10 & 21.40 \\
\hline Monodical P & 0.77 & 0.81 & Oil A & 7.44 & 4.49 \\
\hline L-Valine & 0.05 & - & Oil B & 8.05 & 5.26 \\
\hline Phytase 4 & 0.04 & 0.04 & NDF & 7.31 & 8.1 \\
\hline Premix ${ }^{5}$ & 0.50 & 0.50 & Ash & 5.40 & 5.2 \\
\hline
\end{tabular}

${ }^{1} \mathrm{NDF}=$ neutral detergent fibre; $\mathrm{SID}=$ standard ileal digestible.

2 Oil A = crude fat; ether extractable portion; contains additional non-polar (ether soluble) components of diet.

${ }^{3}$ Oil $\mathrm{B}=$ total fat; acid hydrolysis prior to ether extraction released any bound/ protected fats so that they can be extracted in the ether extract stage.

${ }^{4} 6$-phytase at 2,000 units/ $\mathrm{kg}$ feed.

${ }^{5}$ Premix additives (per kg feed):vitamin A (3a672a retinyl acetate) 8,000 IU, vitamin D3 (3a671 cholecalciferol) 1,500 IU, vitamin E (all rac-alpha tocopherol acetate) (3a700) $125 \mathrm{IU}$, iodine (calcium iodate anhydrous 3b202) $1 \mathrm{mg}$, manganese (manganous oxide 3b502) $30 \mathrm{mg}$, copper (copper sulphate pentahydrate E4-copper) $80 \mathrm{mg}$, iron (iron sulphate monohydrate 3b103) $120 \mathrm{mg}$, selenium (sodium selenite E8-selenium) $0.25 \mathrm{mg}, 1,220 \mathrm{U}$ endo-1-4-beta-xylanase (EC 3.2.1.8), 152 U endo-1,3(4)-beta glucanase (EC3.2.1.6), $5 \mathrm{mg}$ butylated hydroxytoluene (BHT E321). 
test. Significantly different means were separated using the Tukey's post-hoc test. Data are presented as leastsquare means along with the pooled SEM. Significance was assigned at $P<0.05$ and $P>0.05$ and $<0.1$ were denoted trends. Faecal and health scores were analysed by Kruskal-Wallis using the non-parametric function of SPSS. Antibiotic usage was analysed by chi-square analysis. Incidence of death or pigs removed from the trial were not analysed statistically, due to insufficient observations. Data were analysed in terms of pen body weight at the start of the trial and weekly thereafter, feed intake (as average daily feed intake; ADFI) and daily liveweight gain (ADLG) calculated from measurements taken each week, weekly FCR, health and faecal scores.

\section{Results}

Growth performance and health results are presented in Table 3. Initial growth rates were slightly higher than average for this facility at $348 \mathrm{~g} / \mathrm{pig} / \mathrm{d}( \pm \mathrm{SD} 70.5)$ during the first three weeks post-weaning. This higher performance was maintained throughout the study, with pigs gaining an average of $432 \mathrm{~g} \mathrm{BW} / \mathrm{d}( \pm$ SD 80.2) and consuming an average of $510 \mathrm{~g}$ feed/pig/d ( \pm SD 92.1) over the $27 \mathrm{~d}$ experimental period. Over the course of the study, pigs consumed similar amounts of feed and grew at similar rates, irrespective of treatment, and overall FCR and body weights at the end of the study were comparable between treatments. Animals offered the $\mathrm{BA}$ or the $\mathrm{BA}_{\text {low }} / \mathrm{MCOA}$ treatment performed similarly throughout the trial, and although not statistically significant from the other treatments, achieved the highest growth rates. Those receiving BA were, on average, $466 \mathrm{~g}$ heavier at the end of the study than those receiving feed without BA. Between 8-14 d, FCR for pigs receiving BA was better than the negative control diet (1.02 vs $1.17 ; P<0.05)$. The FCR for pigs receiving $\mathrm{BA}_{\text {low }} / \mathrm{MCOA}$ was improved compared to the negative control diet between 0-14 d $(P=0.084)$ and 8-14 $\mathrm{d}(P<0.01)$. In the period $0-14 \mathrm{~d}$, the FCR of pigs receiving the MCOA or $\mathrm{MCOA}_{\text {low }}$ diets was not significantly different from the control diet. Improved FCR in the $\mathrm{BA}(P<0.05)$ and $\mathrm{BA}_{\text {low }} / \mathrm{MCOA}(P=0.084)$ treatments was not seen in phase 2 or over the whole period.

Pigs were in good health generally with a low overall health score of $0.07( \pm$ SD 0.10$)$, irrespective of dietary treatment, and there were no mortalities. The number of pigs removed

Table 3. Growth performance and health status of pigs fed medium chain organic acids in place of benzoic acid or zinc oxide. ${ }^{1,2}$

\begin{tabular}{|c|c|c|c|c|c|c|c|c|}
\hline Parameter & CON & $\mathrm{ZnO}$ & BA & $\mathrm{BA}_{\text {low }} / \mathrm{MCOA}$ & MCOA & $\mathrm{MCOA}_{\text {low }}$ & S.E.M. & $P$-value \\
\hline $\begin{array}{l}\text { Weaning age } \\
\text { Liveweight (kg) }\end{array}$ & \multicolumn{7}{|c|}{ Liveweight (kg) } & 0.996 \\
\hline d 0 & 8.17 & 8.13 & 8.12 & 8.15 & 8.21 & 8.08 & 0.528 & 1.000 \\
\hline d 7 & 9.18 & 9.14 & 8.98 & 9.25 & 9.35 & 9.09 & 0.103 & 0.201 \\
\hline d 14 & 11.39 & 11.49 & 11.73 & 11.84 & 11.66 & 11.53 & 0.213 & 0.702 \\
\hline d 21 & 15.13 & 15.33 & 15.90 & 15.79 & 15.36 & 15.19 & 0.317 & 0.417 \\
\hline d 27 & 19.73 & 19.55 & 20.11 & 20.16 & 19.77 & 19.63 & 0.423 & 0.874 \\
\hline \multicolumn{9}{|l|}{ LSM ADFI (g/d) } \\
\hline d $0-7$ & 191 & 184 & 167 & 195 & 200 & 187 & 10.7 & 0.348 \\
\hline d 8-14 & 345 & 338 & 356 & 355 & 349 & 334 & 14.1 & 0.846 \\
\hline d $15-21$ & 656 & 640 & 689 & 681 & 633 & 640 & 22.2 & 0.359 \\
\hline d 22-27 & 947 & 866 & 935 & 936 & 889 & 929 & 31.1 & 0.406 \\
\hline $0-14 d$ & 268 & 261 & 261 & 273 & 274 & 260 & 11.1 & 0.877 \\
\hline $15-27 d$ & 790 & 744 & 903 & 799 & 751 & 773 & 23.9 & 0.390 \\
\hline \multirow{2}{*}{\multicolumn{9}{|c|}{ LSM ADLG (g/d) }} \\
\hline & & & & & & & & \\
\hline d 0-7 & 145 & 144 & 123 & 158 & 162 & 144 & 14.8 & 0.514 \\
\hline d 8-14 & 313 & 337 & 386 & 361 & 329 & 339 & 19.3 & 0.145 \\
\hline d $15-21$ & 534 & 547 & 595 & 565 & 529 & 511 & 24.5 & 0.221 \\
\hline d 22-27 & 766 & 704 & 702 & 728 & 735 & 740 & 36.1 & 0.815 \\
\hline $0-14 d$ & 230 & 240 & 256 & 262 & 246 & 245 & 15.0 & 0.731 \\
\hline $15-27 d$ & 641 & 620 & 645 & 640 & 624 & 617 & 21.8 & 0.901 \\
\hline Overall & 428 & 423 & 443 & 444 & 428 & 427 & 15.5 & 0.884 \\
\hline \multicolumn{9}{|l|}{ LSM FCR } \\
\hline $0-7 d$ & 1.22 & 1.17 & 1.17 & 1.18 & 1.18 & 1.18 & 0.027 & 0.857 \\
\hline $8-14 d$ & $1.13^{\mathrm{b}}$ & $1.01^{\mathrm{abc}}$ & $0.93^{c}$ & $1.00^{\mathrm{ac}}$ & $1.06^{\mathrm{ab}}$ & $1.01^{\mathrm{abc}}$ & 0.028 & $<0.01$ \\
\hline $0-14 d^{3}$ & $1.17^{\mathrm{a}}$ & $1.0 g^{a b}$ & $1.02^{b}$ & $1.06^{\mathrm{ab}}$ & $1.12^{\mathrm{ab}}$ & $1.08^{a b}$ & 0.028 & $<0.05$ \\
\hline $15-27 d$ & 1.26 & 1.21 & 1.24 & 1.25 & 1.21 & 1.26 & 0.031 & 0.755 \\
\hline Overall & 1.22 & 1.17 & 1.17 & 1.18 & 1.18 & 1.18 & 0.026 & 0.755 \\
\hline Antibiotics ${ }^{4}$ & 11 & 6 & 6 & 8 & 7 & 7 & & \\
\hline Taken off trial (d) & $1(\mathrm{~d} 15)$ & 0 & $1(\mathrm{~d} 13)$ & $1(\mathrm{~d} 8)$ & 0 & $1(\mathrm{~d} 13)$ & & \\
\hline Reason & lame & - & poor health & abscess & - & poor health & & \\
\hline
\end{tabular}

${ }^{1} \mathrm{ADFI}=$ average daily feed intake; $\mathrm{ADLG}=$ average daily liveweight gain; $B A=$ benzoic acid; Con = control; $F C R=$ feed conversion ratio; $L S M=$ least squares mean; $\mathrm{MCOA}=$ Medium chain organic acids; $\mathrm{ZnO}=$ zinc oxide.

${ }^{2}$ Means within row that do not share a common superscript letter differ significantly $(P<0.05)$.

${ }^{3}$ Con vs $\left[\mathrm{BA}_{\text {Iow }} / \mathrm{MCOA}\right], P=0.084$.

${ }^{4}$ No. of pigs requiring antibiotic treatment; standard treatment of amoxycillin $15 \mathrm{mg} / \mathrm{kg} / \mathrm{day}$ for 5 days. 
from the trial was relatively low, at four. A total of 45 pigs (18.8\%) required antibiotic treatment during the trial, with numbers equally distributed between the six treatments. Overall faecal consistency scores were uniformly good throughout the trial (mean $=2.11 \pm 0.09$; 'soft') with no differences observed between the treatments $(P=0.180)$.

\section{Discussion}

The objective of this study was to test the concept of using $\mathrm{MCOA}$ in place of $\mathrm{ZnO}$ in pig weaner diets, either alone or as a partial replacement to BA. Benzoic acid, which is commonly used in commercial weaner diets in the UK, was used as a performance benchmark. There was a noticeable improvement in FCR in pigs receiving the BA treatment, and a lesser improvement for those receiving the $\mathrm{BA}_{\text {low }} /$ MCOA treatment. The performance improvements were visible from the growth and health measurements, which indicated there were no post-weaning health issues. In the second week of the study (d 8-14), only the BA-treated animals (BA and $\mathrm{BA}_{\text {low }} / \mathrm{MCOA}$ ) showed improvements in FCR, whereas those receiving $\mathrm{ZnO}$ showed no improvement in any growth performance parameters. The absence of any measurable effect of $\mathrm{ZnO}$ was likely due to the high health status of the animals in this study, as indicated by clinical health scores and faecal scores. Further studies should be conducted to assess the effects of the treatments under challenge conditions.

Animals offered the $\mathrm{BA}$ or the $\mathrm{BA}_{\text {low }} / \mathrm{MCOA}$ treatments had the highest growth rates. Previous trials showed that ADLG increased by between 9 and 20\% when BA was included at $5,000 \mathrm{mg} / \mathrm{kg}$ in feed (EFSA, 2005). However, such improvements were not seen in the current study, which may have been due to the relatively high growth rate. In previous studies (Portocarero, 2022) using a similar randomised bock design, a blend of MCOA consisting of C6:0, C8:0, C10:0 and C12:0 was compared with $\mathrm{ZnO}$ and BA from weaning to $56 \mathrm{~d}$ post-weaning. Low initial growth rates were linked to high antibiotic usage and the removal of poorly performing pigs. Animals receiving BA plus MCOA or BA plus $\mathrm{ZnO}$ showed superior FCR and ADLG throughout the trial in comparison to the control diet. Dietary treatment influenced FCR throughout the study, with improvements reported for pigs fed BA plus MCOA compared to the control diet $(P=0.008)$. A second study, carried out for 28 days post-weaning, compared a low and high inclusion level of MCOA plus $\mathrm{ZnO}$ and with a blend of either C6:0 and C12:0 or C6:0 and C12 monolaurin. An inclusion level of $1,500 \mathrm{mg} / \mathrm{kg}$ MCOA resulted in an improved FCR in pigs at three and four weeks after weaning $(P<0.05)$, compared to the control diet. Pigs fed a blend of caproic acid plus monolaurin or caproic acid plus lauric acid showed similar FCR improvements to the pigs receiving blended C6:0, C8:0, C10:0, and C12:0.
The improvement in FCR seen in the $\mathrm{BA}_{\text {low }} / \mathrm{MCOA}$ treatment group in the current study was encouraging as it confirmed that the dose rate of BA can be reduced and substituted with MCOA, without any reduction in performance. In grower-finisher diets, the recommended dose rate of 5,000 mg BA/ kg feed was reduced (Regulation (EU) $2020 / 1031$ of 15 July 2020), and the current results demonstrated that the lower level was still effective.

No improvements in ADLG due to MCOA were seen in this study. Other trials showed mixed results in response to MCOA. Hanczakowska et al. (2013) found that piglets receiving C8:0 caprylic acid, C10:0 capric acid, or a mixture of both from seven days of age had improved ADLG and FCR $(P<0.05)$ by d 35 compared to the control group. ADLG was improved by $13-18.7 \%$ throughout the $84 \mathrm{~d}$ study. Gebhardt et al. (2020) reported linear increases in ADLG and ADFI $(P<0.01)$ and FCR $(P=0.004)$ when a 1:1:1 blend of $C 6: 0, C 8: 0$ and $C 10: 0$ was included at $1.5 \%$ in the diet. Thomas et al. (2020) found a linear increase in ADLG $(P<0.001)$ when $2 \%$ of a blended C8:0/ C10:0 product was added to feed, and a linear increase in FCR at up to $1 \%$ inclusion. In contrast, only a $2.8 \%$ increase in ADLG was recorded with $2 \%$ MCOA in feed (Mohana Devi and Kim, 2014). Furthermore, Dahmer et al. (2020) found that a blend of C6:0, C8:0 and C10:0 did not significantly affect performance compared to a negative control diet, whereas $\mathrm{ZnO}(3,000 \mathrm{mg} / \mathrm{kg})$ improved ADLG $(P<0.001)$ but the inclusion level of MCOA was not specified. The size of response was likely influenced by the type and dose rate of MCOA and pathogen challenge. The current study demonstrated measurable improvements in feed conversion efficiency in response to a combination of BA, caproic acid and monolaurin, even when the background health and growth performance was good. However, effects of caproic acid and monolaurin in the absence of BA were inconclusive.

\section{Conclusions}

The addition of $5,000 \mathrm{mg} / \mathrm{kg} \mathrm{BA}$ to an unmedicated weaner diet improved FCR. When the BA inclusion level was reduced to $2,500 \mathrm{mg} / \mathrm{kg}$ and the diet was further supplemented with monolaurin and caproic acid, FCR improvements were largely maintained. This suggested that medium chain organic acids including monolaurin and caproic acid may be used to partially replace BA in piglet diets and as part of a strategy to replace $\mathrm{ZnO}$ without resorting to antibiotic use.

\section{Conflict of interest}

The authors declare no conflict of interest. 


\section{References}

Agriculture and Horticulture Development Board (AHDB), 2019. Report: pig industry antibiotic results show further reduction. AHDB, Kenilworth, UK. Available at: https://ahdb.org.uk/news/ pig-industry-antibiotic-results-show-further-reduction

Agriculture and Horticulture Development Board (AHDB), 2020. Report: pig sector continues to reduce antibiotic use. AHDB, Kenilworth, UK. Available at: https://ahdb.org.uk/news/pig-sectorcontinues-to-reduce-antibiotic-use

Batovska, D.I., Todorova, I.T., Tsvetkova, I.V. and Najdenski, H.M., 2009. Antibacterial study of the medium chain fatty acids and their 1-monoglycerides: individual effects and synergistic relationship. Polish Journal of Microbiology 58: 43-47.

Dahmer, P.L., Leubcke, G.E., Lerner, A.B. and Jones, C.K., 2020. Effects of medium-chain fatty acids as alternatives to $\mathrm{ZnO}$ or antibiotics in nursery pig diets. Translational Animal Science 4: 1-8. https:// doi.org/10.1093/tas/txaa151

European Commission, 2017. Commission implementing decision of 26.6.2017 concerning, in the framework of Article 35 of Directive 2001/82/EC of the European Parliament and of the Council, the marketing authorisations for veterinary medicinal products containing 'zinc oxide' to be administered orally to food producing species. European Commission, Brussels, Belgium. Available at: https://tinyurl.com/3ws3rk48

European Food Safety Authority (EFSA), 2005. Opinion of the Scientific Panel on additives and products or substances used in animal feed on the safety and efficacy of the product $\mathrm{VevoVitall}^{\oplus}$ as a feed additive for weaned piglets in accordance with Regulation (EC) No 1831/2003. EFSA Journal 290: 1-13.

Gebhardt, J.T., Thomson, K.A., Woodworth, J.C., Dritz, S.S., Tokach, M.D., DeRouchey, J.M., Goodband, R.D., Jones, C.K., Cochrane, R.A., Niederwerder, M.C., Fernando, S., Abbas, W. and Burkey, T.E., 2020. Effect of dietary medium-chain fatty acids on nursery pig growth performance, fecal microbial composition, and mitigation properties against porcine epidemic diarrhea virus following storage. Journal of Animal Science 98(1). https://doi.org/10.1093/jas/skz358

Hanczakowska, E., 2017. The use of medium-chain fatty acids in piglet feeding - a review. Annals of Animal Science 17(4): 967-977. https://doi.org/10.1515/aoas-2016-0099

Hanczakowska, E., Szewczyk, A., Świątkiewicz, M. and Okoń, K., 2013. Short and medium-chain fatty acids as a feed supplement for weaning and nursery pigs. Polish Journal of Veterinary Sciences 16: 647-654. https://doi.org/10.2478/pjvs-2013-0092

Hassinen, J.B., Durbin, G.T. and Bernhart, F.W., 1951. The bacteriostatic effects of saturated fatty acids. Archives of Biochemistry and Biophysics 31: 183-189. https://doi.org/10.1016/00039861(51)90204-4

Holmer, I., Salomonsen, C.M., Jorsal, S.E., Astrup, L.B., Jensen, V.F., Høg, B.B. and Pedersen, K., 2019. Antibiotic resistance in porcine pathogenic bacteria and relation to antibiotic usage. BMC Veterinary Research 15: 449. https://doi.org/10.1186/s12917-019-2162-8

Marounek, M., Skrivanová, E. and Rada, V., 2003. Susceptibility of Escherichia coli to C2-C18 fatty acids. Folia Microbiologica 48: 731-735. https://doi.org/10.1007/BF02931506
Mohana Devi, S. and Kim, I.H., 2014. Effect of medium chain fatty acids (MCFA) and probiotic (Enterococcus faecium) supplementation on the growth performance, digestibility, and blood profiles in weanling pigs. Veterinarni Medicina 59: 527-535. https://doi. org/10.17221/7817-VETMED

Munita, J.M. and Arias. C.A., 2016. Mechanisms of antibiotic resistance. Microbiology Spectrum 4(2). https://doi.org/10.1128/ microbiolspec.VMBF-0016-2015

National Pig Association (NPA), 2017. The future of zinc oxide - an evidence-based decision or a political stitch-up? Pig World, March 3. Available at: https://tinyurl.com/2p8t5ndv

Neath, C., Portocarero, N. and Jones, C., in press. In vitro susceptibility of swine pathogens to feed additives and active ingredients with potential as antibiotic replacements. Journal of Applied Microbiology. https://doi.org/10.1111/jam.15318

Nieman, C., 1954. Influence of trace amounts of fatty acids on the growth of microorganisms. Bacteriological Reviews 18: 147-163. https://doi.org/10.1128/br.18.2.147-163.1954

Pollock, J., Muwonge, A., Hutchings, M.R., Mainda, G., Bronsvoort, B.M., Gally, D.L. and Corbishley, A., 2020. Resistance to change: AMR gene dynamics on a commercial pig farm with high antimicrobial usage. Scientific Reports 10: 1708. https://doi.org/10.1038/s41598020-58659-3

Portocarero, N., 2022. Comparison of medium chain organic acids with $\mathrm{ZnO}$ and benzoic acid; effect on growth performance of pigs. Journal of Applied Animal Nutrition, in press. https://doi.org/10.3920/ JAAN2021.0012

ProHealth FP7 consortium, 2015. Cost of production diseases. Available at: https://www.fp7-prohealth.eu/knowledge-platform/ newsletter-articles/production-diseases-the-cost/.

Responsible Use of Medicines in Agriculture (RUMA), 2020. Target task force report: responsible use of antibiotics in UK farming, progress against 2020 targets, new targets 2021-2024. Available at: https://tinyurl.com/ycx7ky6c

Shilling, M., Matt, L., Rubin, E., Visitacion, M.P., Haller, N.A., Grey, S.F. and Woolverton, C.J., 2013. Antimicrobial effects of virgin coconut oil and its medium-chain fatty acids on Clostridium difficile. Journal of Medicinal Food 16: 1079-1085. https://doi.org/10.1089/jmf.2012.0303 Skrivanová, E., Marounek, M., Benda, V. and Brezina, P., 2006. Susceptibility of Escherichia coli, Salmonella sp. and Clostridium perfringens to organic acids and monolaurin. Veterinarni Medicina 51: 81-88. https://doi.org/10.17221/5524-VETMED

Thomas, L.L., Woodworth, J.C., Tokach, M.D., Dritz, S.S., DeRouchey, J.M., Goodband, R.D., Williams, H.E., Hartman, A.R, Mellick, D.J., McKilligan, D.M. and Jones, A.M., 2020. Evaluation of different blends of medium-chain fatty acids, lactic acid, and monolaurin on nursery pig growth performance. Translational Animal Science 4: 548-557. https://doi.org/10.1093/tas/txaa024

Woolhouse, M., Ward, M., Van Bunnik, B. and Farrar, J., 2015. Antimicrobial resistance in humans, livestock and the wider environment. Philosophical Transactions of the Royal Society B 370: 20140083. https://doi.org/10.1098/rstb.2014.0083

Zhang, B., Ku, X., Yu, X., Sun, Q., Wu, H., Chen, F., Zhang, X., Guo, L., Tang, X. and He, Q., 2019. Prevalence and antimicrobial susceptibilities of bacterial pathogens in Chinese pig farms from 2013 to 2017. Scientific Reports 9: 9908. https://doi.org/10.1038/ s41598-019-45482-8 